
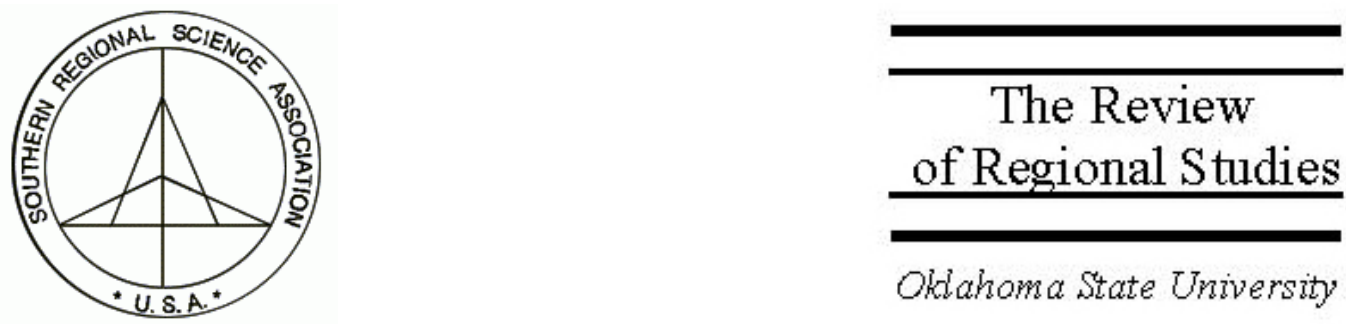

\title{
Regional Policies and Economic Growth: One Size Does Not Fit All
}

\author{
Denys Nizalov \\ Department of Agricultural Economics, Michigan State University, \\ East Lansing, MI, 48824, e-mail: nizalovd@msu.edu \\ Scott Loveridge \\ Department of Agricultural Economics, Michigan State University, \\ East Lansing, MI, 48824, e-mail: loverid2@msu.edu
}

\begin{abstract}
We analyze the impact of economic development policies and highway infrastructure improvements on growth of per capita income and jobs in Michigan counties. The policies considered for analysis have significant impact on growth outcomes. However, this effect is non-linear. Significant heterogeneity in policy effects is also detected. The impacts are different with respect to average income level in a county as well as between metropolitan and non-metropolitan areas. In addition, cross-policy effects are found. We use improved measurement of policy treatment while accounting for possible spillover effects.
\end{abstract}

Keywords: Regional economic development; Policy analysis; Michigan; Counties; Heterogeneity

JEL classification: $018 ;$ R11; $R 58$

Earlier versions of the paper were presented at the 50th Annual North American Meeting of the Regional Science Association International, November 2003, and at the annual conference of the American Agricultural Economics Association, July 2005. The paper has benefited greatly from comments by Sonya M. Glavac, the conference participants, two anonymous referees, and RRS editor Dan Rickman. 
Nizalov/Loveridge: Regional Policies and Economic Growth

\section{INTRODUCTION AND OBJECTIVES}

The growth rate and the distribution of personal income are among the major characteristics of well being of a local population. They are also issues of concern for all levels of government. As a result, a large number of federal and local economic development policies and programs are aimed at personal income growth. Such programs include improvement of public infrastructure, job training, grants, loans, tax abatements for business expansion and retention, etc. For example, in the year 2000 Michigan had more than 40 programs and policy tools specifically aimed at economic development (Citizens Research Council of Michigan [CRC] 2001). However, with many states currently facing budget difficulties, the role of state government in economic development is likely to be challenged with increasing frequency. The effectiveness of development policies and programs in raising income is therefore an important question.

There is a large literature on economic development program evaluation, but there is no consistency in the results. Some authors found no significant relationship between policies and growth, while findings of others vary greatly. (For reviews, see Bartik 1991; Fisher 1997; Wasylenko 1997; Goss and Phillips 1999; Buss 2001.) The reasons for the variation in findings are numerous. Among them are the quality of data (Buss 2001), deviation of true political goals from the optimal economic development path of a region (Wolcoff 1992; Dewar 1998; Thornburgh 1998), imperfections in policy evaluation methods (Bartik 1991; Buss 2001), and shortcomings in policy design.

This paper addresses some of the above-mentioned concerns. However, there are some less studied issues that contribute to the lack of consistency in empirical policy assessments. The first of them is that the same policies may have significantly different effects in different geographic areas due to the heterogeneity of local economies. This heterogeneity leads to an aggregation error and non-systematic empirical results (Forni and Lippi 1997). Separate estimation of policy effects in counties with relatively high and low income, different industry structure, and level of urbanization is undertaken to assess the extent of the aggregation error issue.

Some support for the heterogeneity concern can be found in the literature. Loh (1993) finds that effect of development policies on job growth differs across industries. He finds also that the effects of different policies on the same outcome are different, as well as the effect of the same policy on different measures of growth. Similar evidence is found by Dalenberg and Partridge (1995), Luce (1994), and Papke (1991). Fisher (1997) suggests that this heterogeneity can be explained by different marginal return to factors targeted by the policies across industries and sectors. The marginal return may also differ with respect to average income level and between metropolitan and non-metropolitan areas. Another source of heterogeneity is related to possible differences in the size of the marginal effects of policy under different scales of policy application. If under these circumstances, the intensity of policy application is systematically different among subregions of a state, the marginal policy effect should also be different. 
Another rarely addressed problem in policy analysis is that a large number of policies and programs are implemented simultaneously. Several of them are either mutually exclusive or additive by design. On the one hand, this fact may lead to mixing the impacts of different policies. On the other hand, programs may have mutually increasing or decreasing effect. To address these issues, we consider the effect of several policies at the same time.

The above-mentioned issues can be restated in the following hypotheses.

- The impacts of development policies vary with respect to an average income level, industrial structure, and degree of urbanization of local economy.

- The policy effects are not linear.

- The effect of any development policy is conditional on the presence of other policies in a region.

To test these hypotheses, this study analyzes the impacts of Michigan economic development policies and improvements in highway infrastructure on county per capita income and job growth in the 1990s. Focusing on the economy of just one state helps control for unobservable factors such as the legal system, culture, other statewide institutions, and natural amenities. Loh (1993) mentions that such an approach would greatly improve the quality of data on development policies since comparability is no longer an issue.

Several other issues raised in the literature are also addressed. First, an attempt is made to improve the measurement of policy treatments. Previous studies use the presence or absence of policy treatment in an area (e.g., state) to identify the policy effect. Other studies look at the number of development programs available in a region. (For review, see Fisher and Peters 1997.) In contrast, to quantify the policy shock to a local economy, we use more precise measures. The intensity of policy use is measured by number of businesses receiving a benefit (e.g., tax break) or by area of a zone receiving a policy benefit. This approach allows assessing the effect of marginal change in the treatment on growth outcomes (e.g., providing policy benefits to one additional business) - an issue that has important policy implications.

Second, a policy treatment may have a significant spillover effect on neighboring areas (Bartik 1991; Papke 1993, 1994; Fisher 1997). This effect arises due to regional production and consumption relationships (multiplier effect), migration, and commuting patterns. While policies are applied to small territories of a neighborhood or a township size, a county is used as a unit of analysis. ${ }^{1}$ The area of a county captures additional benefits of a policy applied to a small territory within a county.

\footnotetext{
${ }^{1}$ One could argue that a county is a too large area to capture the effect of treatment applied to just one business establishment or the effect of a small tax-free zone. However, if anything, we would underestimate the policy effect since local commuting zones normally include several counties (Tolbert and Sizer 1996). Supply and demand chains are even more widely distributed than commuting.
} 
The rest of the paper is structured in the following way. Part 2 provides a brief introduction to the Michigan economy and explains the nature of the economic development policies under consideration. Next, we turn to the justification of the empirical model used for policy analysis. Part 4 describes the data. Discussion of the results is presented in part 5. Part 6 concludes the paper.

\section{MICHIGAN DEVELOPMENT POLICIES}

Michigan is a heavily industrialized state. While its population accounts for 3.5 percent of the U.S. total (Census Bureau 2000), the state contribution to national manufacturing output was 5.4 percent in 2000 (Bureau of Economic Analysis [BEA] 2005). Motor Vehicles Manufacturing is an important industry for the Michigan economy. While major facilities are in metropolitan areas, the auto companies have outsourced many components to small manufacturers across the state, providing employment outside the metropolitan areas.

During the 1990 s Michigan real personal income per capita ${ }^{2}$ grew at an average annual rate of 1.9 percent, slightly outpacing the national average of 1.6 percent. The job growth was, on average, 0.9 percent per year, compared to 0.6 percent for the nation (BEA 2005).

Even though the state economy went through structural changes contributing to the growth, this period is also known for an aggressive role of state and local government in economic development (Bartik, Eisinger, and Erickcek 2003; CRC 2001). Those efforts were mirrored in the sharp increase of the state's "Governor's Cup" ranking published by Site Selection, an economic development trade publication. The Governor's Cup is an annual ranking of states based on the reported number of major new investments in business re-location and expansion. ${ }^{3}$ After placing fifteenth in 1993 and twenty-second in 1994, Michigan recovered to seventh place in 1995 and sixth in 1996. In 1997, Michigan started a string of first-place rankings that continued for four consecutive years before it dropped to fourth place in 2001, second in 2002, and fifth in 2003.

However, the contribution of the government to this improvement may be quite limited; the various types of business expansion (jobs created, new buildings, or financial investments) included in the ranking may not depend exclusively on the existence of a particular policy. For example, with respect to job creation, Faulk (2002) finds that only around 25 percent of new jobs claimed by policy beneficiaries can be attributed to the policy effect. The rest would have been created anyway. A similar number is reported by Papke (1994). Moreover, Fisher and Peters (1997) argue that a policy effect on job

\footnotetext{
${ }^{2}$ Real income is considered throughout this paper.

${ }^{3}$ Based on number of new and expanded facilities in terms of jobs, square footage, or dollars invested. The ranking does not control for state population. According to the U.S. Census Bureau, Michigan is the eighth most populous state.
} 
growth can be negative due to factor substitution. Thus, a careful evaluation of policy effects on growth is necessary.

This article focuses on a group of policies initiated during the 1990s that have been implemented in a substantial proportion of Michigan counties. The effect of those new policies is compared to a more traditional development tool: road infrastructure. The policies considered for the analysis are the following.

\subsection{The Michigan Economic Growth Authority}

The Michigan Economic Growth Authority (MEGA) program grants eligible businesses with Single Business and Income tax credits for 8 to 20 years. The program targets "large-scale investment and job creation [and retention], as well as attraction of technology-intensive business" (CRC 2001, p. 20). The purpose of the program is to support the projects that would not occur without the policy support. ${ }^{4}$ There is no targeting of specific geographic areas. However, businesses located in federally designated distressed zones have a lower eligibility threshold. Also, some industry restrictions apply.

The program started in 1995; by the end of 2000, there were 107 authorities located in 30 counties that directly and indirectly created 145,542 jobs. $^{5}$ The number of MEGAs per 100,000 county residents measures the treatment. The intensity of this normalized treatment ranges from 0 to 14.3 and averages 0.3 MEGAs per county. (See Table 1 for more details.)

Bradshaw (2002) reports that roughly 70 percent of new jobs generated by expanded or new businesses are created during the first year of the expansion. For that reason we would expect much of the effect of MEGAs on job growth to be short run. New employment leads to additional labor income, which in turn is partially diverted to neighboring communities by commuters. Thus, it is reasonable to expect MEGA's effect on income growth to be lower than the effect on job growth. However, the consumption linkages of new workers and supply/demand linkages of firms benefiting from MEGAs would amplify the policy effect in the longer run.

Even though county economic conditions do not enter the formal eligibility criteria, endogeneity of MEGA's effects may occur if more of the eligible business establishments are attracted to counties with higher growth potential. If this were true, a simple correlation between the number of MEGAs and growth would include upward bias. The issue of endogeneity of policy treatment is addressed in more detail in section 3 of this paper.

\footnotetext{
4 “... applicants must certify that the project would not occur absent the MEGA grant." (CRC 2001, p. 20).

${ }^{5}$ Based on estimates by Michigan Economic Development Corporation.
} 
The estimated effect of RZ on growth may be biased downward. The policy targets areas with lower potential for growth, and counties with larger per capita area of the zone would also have more distressed areas, controlling for population density. However, Wooldridge (2002), considering the example by Papke (1994), argues that the presence of a policy treatment in a county is not conditional on county performance once a zone is designated. Thus, there is no significant endogeneity in policy treatment after controlling for county-specific conditions. The same argument can be applied to other policies under consideration.

\subsection{The Brownfield Development Authority}

The Brownfield Development Authority (BDA) program targets re-development of "blighted," "functionally obsolete," and contaminated sites (CRC 2001, p. 31). BDAs are allowed to use tax increment for redevelopment of the Brownfield sites. In addition, there are state bonds "dedicated to Brownfield remediation." Also, the BDA's projects are eligible for Single Business Tax credits. Michigan adopted the program in 1996; by the end of 2000, there were 170 Authorities located in 53 counties. We use the number of BDAs in a county per 100,000 residents to quantify the policy treatment. Its intensity averages 0.4 authorities per county. (See Table 1 for details.)

The immediate job growth effect generated by the $\mathrm{BDA}^{7}$ program is expected to be small because it is limited to temporary jobs associated with the environmental remediation phase of the redevelopment effort. However, BDAs bring previously underutilized land into active economic use, increasing property value. For that reason, the effect of BDAs on income growth is expected to be positive and significant. Two factors operate in opposite directions in terms of bias. More distressed areas would potentially have a higher number of Brownfields available for redevelopment; but, on the other hand, higher demand for sites is expected in faster growing areas.

\subsection{Highway Infrastructure}

Improvement in highway infrastructure is another development tool. It may lead to a reduction in commuting time and transportation cost, contributing to long-term growth of both income and number of jobs. The effect of highways is measured in terms of miles of federal, state, and major county highways and roads per 1,000 residents. Michigan has on average 3.8 miles per 1,000 county residents. (See Table 1 for details.) Construction of major roads follows a long-term plan and is funded primarily through state and federal budgets, reducing the bias in the policy treatment.

The data on the policies come from the Michigan Economic Development Corporation, Citizens Research Council of Michigan. and the State of Michigan government. Policy treatment is measured as of January 1 of a given year.

\footnotetext{
${ }^{7}$ For discussion, see Mayer and Lyons (2000), DeSousa (2000).
} 
The set of policies under consideration does not include some important programs such as direct incentives, job training, loan guarantees, subsidies, etc. This exclusion is driven by data availability and the spatial scale of policy implementation. However, the policies considered in this study are good representatives of four groups of development incentives widely used in other states. MEGA represents a class of firm-level tax abatements. RZ are akin to a wide range of programs targeting revitalization of economically distressed areas (e.g., enterprise zones). BDA represents programs that do not have job growth or business creation/expansion as a primary objective. And finally, highway system expansion is a typical example of infrastructure improvement activity. Moreover, "[of] all the public services examined for an influence on economic development, transportation services, and highway facilities especially, show the most substantial evidence of a relationship" (Fisher 1997, p.54).

\section{EMPIRICAL MODEL}

There are several approaches to the development policy analysis. Among other case studies, simulations and econometric analysis are used most frequently. Each of them has its own benefits and weaknesses (Bartik 1991; Sadoulet and deJanvry 1995; Fisher and Peters 1997; Goss and Phillips 1999). Econometric analysis is the most appropriate to use for testing heterogeneity of policy effects with the policy data described above.

Simple correlation analysis of policy treatments and growth will likely to produce biased estimates of policy effects since, as we argue above, some policies specifically target areas with lower growth rates while some others are likely to be applied more in the areas with higher potential for growth. However, the fact that policy treatments are assigned by state or federal agencies partially reduces endogeneity of policy shock to the current county growth conditions. Other sources of endogeneity are also possible. One is due to endogenous migration or sorting. ${ }^{8}$ That is, areas affected by policies might attract population with some common unobservable characteristic correlated with growth. Another source is due to normalization of policy treatment in our study by population. Since the size of population responds to the growth conditions through migration (Goetz 1999), faster growing regions would experience endogenous reductions in per capita policy treatment, biasing estimates downward.

There are two ways to circumvent the endogeneity problem. First is to estimate the policy effect using instrumental variables (e.g., Goss and Phillips 1999). Second is to control for policy selection criteria within the estimation model. Unfortunately, a plausible set of instruments for the policies under consideration is not available. That leaves us with the second approach, which, however, does not guarantee control for all sources of bias (Besley and Case 2000). Nevertheless, we take several steps to minimize the uncontrolled endogeneity.

\footnotetext{
${ }^{8} \mathrm{We}$ do not consider an endogenous sorting as a serious problem. If that sorting (business relocation and population migration) is a response to the treatment, we consider it as a part of policy outcome for a county, even though no effect may be observed at a macro level.
} 
First, we eliminate bias in normalized policy treatment created by endogenous population change in the following way. The treatment is normalized by population in a year of implementation of that treatment. This normalized treatment is carried over time with no accounting for change in population in later periods. Any changes in the policy treatment itself (e.g., a new authority or additions to a Renaissance Zone) are normalized by population in a year of that change and added to the amount of treatment from the previous period.

Second, we include into the estimation model controls for policy targeting. The first candidates for the controls would be income and job levels per capita since policies target areas with low income and employment. However, those variables are endogenous to the growth by construction of the variables. (Future level is a function of the current level and the growth rate, which is ruled out for the fixed effect estimation procedure used in our analysis.) Instead, we include the following variables that may impact the targeting and influence the growth. The share of people with a bachelor's degree, denoted by educ, controls for the level of education (or human capital) of a county population. The number of jobs per capita in manufacturing (manuf), government (gov), and farming ( farm) serve as controls for the industry structure of each county's economy. Density of business establishments (dens) controls for the degree of concentration and urbanization. ${ }^{9}$ These variables also explain a large portion of variation in income and job levels.

Design and implementation of the policies takes time. Thus, county economic conditions should be controlled in a year when the policy designation decisions are made. Therefore, the control variables are used with a one-year lag. This avoids simultaneity bias in the control variables.

The resulting estimation model takes the following form (1): ${ }^{10}$

$$
\begin{aligned}
& \text { GR }_{t^{\prime}-t}=\beta_{0}+\beta_{1} \text { policy }_{t}+\beta_{2} \text { educ }_{t-1}+\beta_{3} \text { manuf }_{t-1}+\beta_{4} \text { gov }_{t-1} \\
& +\beta_{5} \text { farm }_{t-1}+\beta_{6} \text { dens }_{t-1}+\beta_{7} \text { year }_{t}+e+u_{t}
\end{aligned}
$$

where $G R_{t^{\prime}-t}$ is the growth rate between years $t$ and $t^{\prime}\left(t^{\prime}>t\right)$. Vector $e$ denotes unobserved county conditions that are fixed over time, and $u$ is an idiosyncratic error.

Policies may have different primary objectives (e.g., growth of large versus small businesses, growth versus redistribution of income, etc). Two aspects of policy objectives, income and job growth in a county, are considered in turn. Thus, $G R_{t^{\prime}-t}$ represents in turn each of the two growth outcome measures.

\footnotetext{
${ }^{9}$ In particular, the density variable helps control for possible systematic differences in policy application between rural and urban areas.

${ }^{10}$ The indexes for counties are suppressed.
} 
The timing of the growth response to the policy treatment is an important issue. Some of the responses, such as change in production and employment levels, are relatively fast while others, such as relocation and changes in business birth rates, may take a long time to occur. Also, some policies may have a short-lived effect while others impact long-run growth patterns. This timing differs also for different development outcomes (e.g., job versus income growth) (Papke 1994).

One may argue that short-run fluctuations in a growth rate may be driven primarily by fluctuations in demand and industry specialization. It would be problematic to separate a policy effect if designation of the policy treatment is also driven by these factors. These issues represent a major challenge for our empirical analysis. To address this issue, we first consider two measures of the growth outcomes: over one-year period (annual growth) and three-year average growth rates. The annual measure is designed to capture the most immediate policy effect (if any). The second measure averages out some of the annual fluctuations and is designed to capture more persistent policy effects. Secondly, to control for demand and industry fluctuations (which are most likely to be common for most of the state), we include a set of year binary variables (year) together with measures of industry structure (as described above) in the model. The year dummies also control for common shocks such as inflation, national business activity conditions, etc.

A vector of normalized policy treatments (Policy) is of primary interest. To test the hypothesis about the cross-policy effects, the interaction terms among the policy treatments are also included in the base model. Nonlinearity of the growth response is tested by inclusion of square terms for policy treatment. To test for heterogeneity of policy effects, the model is estimated separately for counties with high and low level of per capita income. The difference between counties with high and low per capita number of jobs in manufacturing and between metropolitan and non-metropolitan counties are also considered and discussed briefly.

The model omits a number of factors relevant to growth. Among them are local taxes, natural amenities, quality of local government, spatial interdependence of the regions, etc. Most of them can be a source of omitted variable bias since they may determine the application of policy. However, these factors have little variability over time. We assume also that other conditions that describe county eligibility for the treatment or attractiveness of a county to MEGA eligible businesses stay stable over time, conditional on other controls. Using eight periods of annual data is consistent with this assumption. ${ }^{11}$ A county-specific effect $(e)$ denotes all time invariant conditions.

\footnotetext{
${ }^{11}$ In using fixed effect transformation of the data, we have to consider a tradeoff between the number of factors that stay stable and the time horizon. The longer the time span, the fewer the number of factors that stay constant and thus are controlled by this estimation technique. The eight-year time period considered in our analysis is thought to be a good balance. It is reasonable to assume that unobservable county conditions that impact an amount of policy treatment are stable over this time period, conditional on other variables in the model. On the other hand, Figure 1 shows that we have a large variation of, for example, annual income growth around the
} 
A fixed effect Feasible Generalized Least Squares (FGLS) procedure is used for estimation of the model. The main benefit of the selected procedure is that it helps control for unobserved fixed factors in the growth model $(e)$ and provides efficient estimates of standard errors. Fixed effect estimation reveals how the change in the treatment for the same entity associates with change in the growth rate controlling for other factors. The FGLS procedure is particularly helpful in estimating three-year average growth where significant serial correlation in the errors is present. Alternative procedures are mentioned in section 5 of this paper.

\section{DATA DESCRIPTION}

Local Area Annual Estimates (BEA 2005) is the primary source of the data for the dependent and control variables for 83 of Michigan counties over the years $1993-2000$, making a total of 664 annual county-level observations. This time frame is determined by the data availability. To get consistent FGLS estimates, the year of 1993 is not used for estimation after fixed effect transformation is performed on the full set of data. Thus, only 581 observations are used by the FGLS procedure.

Four dependent variables are used in our analysis, making a set of four equations. They are annual and three-year average growth in personal income and number of jobs. As an example, consider the year 2000. The annual growth for this year is change in income or job levels between years 2001 and 2000. Three-year average growth is computed as the change between the years 2003 and 2000 divided by three. Figure 1 depicts the patterns of both growth outcomes in Michigan over the 1993-2000 period. There is a 58 percent correlation between annual and three-year average income growth and a 71 percent correlation for the job growth measures. There is a 45 percent positive correlation between annual income and job growth for Michigan counties. Thus, these variables reflect some different aspects of economic growth.

The average annual income growth for Michigan counties was 1.7 percent, varying from minus 11.6 to positive 14.7 percent. Jobs grew at an average rate of 1.1 percent, ranging from minus 15.8 to plus 24.0 percent. (See Table 2 for descriptive statistics.) In our sample, the average share of adults with a bachelor's degree (used to control for education level) is 8.1 percent. There are, on average, 101.1, 68.1, and 5.6 jobs per thousand county residents in manufacturing, government, and farming, respectively. The average concentration of business is 25.1 establishments per square mile.

We pay particular attention to potential heterogeneity of the policy effects across different types of local economies. To compare the growth patterns, we have divided the state into counties with above and below the median per capita personal income levels, called "high" and "low" income counties, respectively. To avoid artificial truncation, we

state average of 1.8 percent per year over 1993-2000. The policy treatment has also a significant variation. 


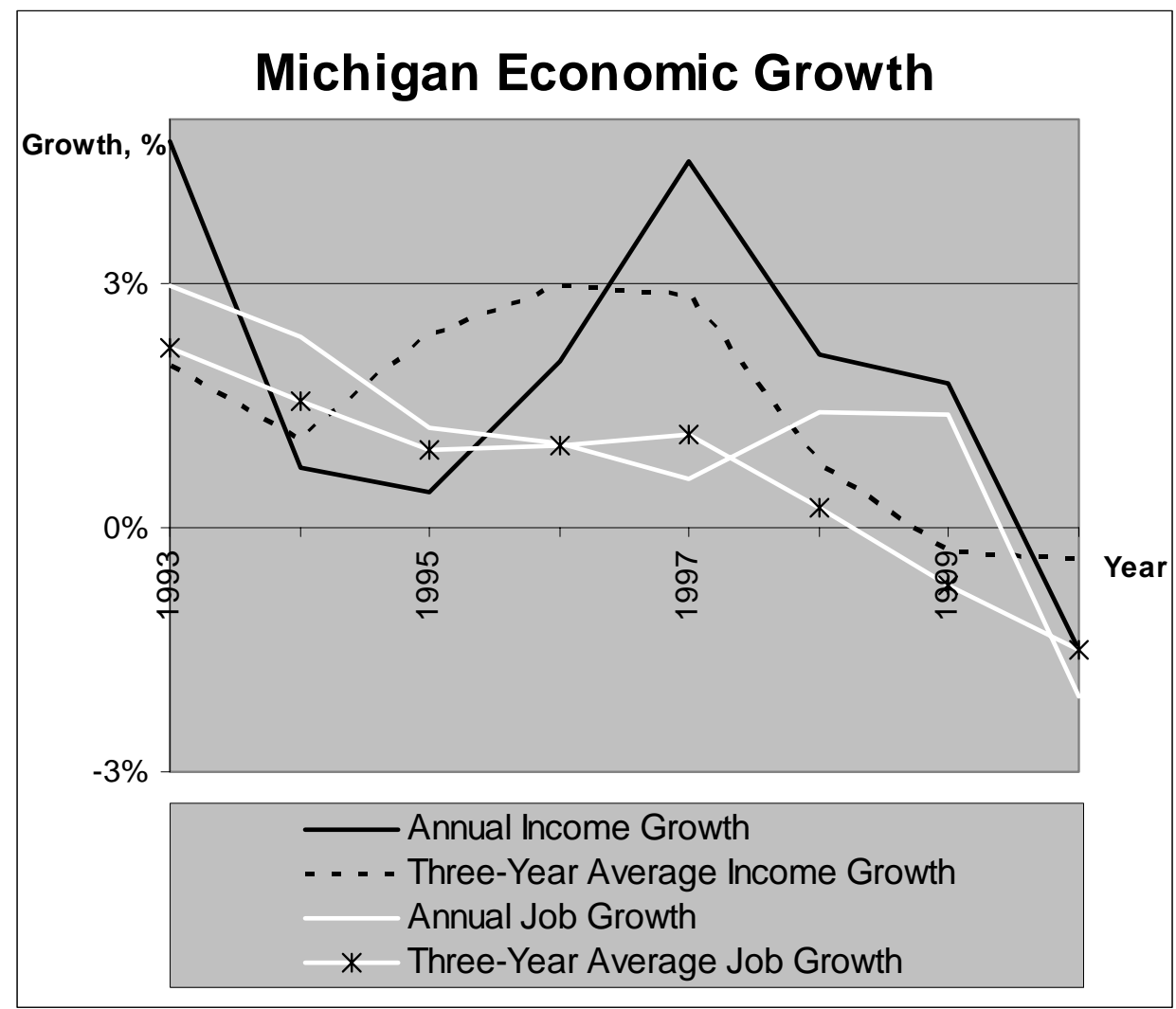

FIGURE 1. Michigan Economic Growth Patterns

Data: Bureau of Economic Analysis; Inflation Adjusted

consider the average income level over eight years for each county for the assignment into the appropriate income group.

The other dimensions of potential heterogeneity are industrial structure of the local economy and degree of urbanization. Counties with more and less than median per capita number of jobs in manufacturing are treated as separate sub-regions for that purpose. The average number of jobs over eight years for each county is considered for this purpose. Counties are also distinguished as metropolitan and non-metropolitan. The metropolitan part includes 41 Michigan metropolitan and metropolitan-adjacent counties (ERS Rural-Urban Codes 0, 1, 2, 3, 4, 6, and 8). The non-metropolitan part includes the other 42 Michigan non-metropolitan, relatively rural counties.

There is a strong correlation among the different classifications of county economies. For example, 39 percent of metropolitan counties also have a high number of manufacturing jobs, and 45 percent of metropolitan counties are in the high-income category. About 55 percent of the high income counties have also a high number of manufacturing 
TABLE 2

Summary Statistics: Michigan Counties, 1993-2000

\begin{tabular}{|c|c|c|c|c|}
\hline Variable & Mean & Std. Dev. & Min & Max \\
\hline Annual Income Growth, ${ }^{a} \%$ & 1.731 & 2.602 & -11.565 & 14.725 \\
\hline Three-Year Average Income Growth, ${ }^{\text {a }} \%$ & 1.317 & 1.562 & -6.841 & 5.308 \\
\hline Annual Job Growth, ${ }^{\text {a }} \%$ & 1.073 & 2.325 & -15.780 & 23.985 \\
\hline Job Growth, ${ }^{\mathrm{a}} \%$ & 0.587 & 1.644 & -8.610 & 12.234 \\
\hline $\begin{array}{l}\text { Percentage of Population with Bachelor } \\
\text { Degree, }{ }^{\mathrm{b}} \%\end{array}$ & 8.140 & 3.217 & 2.977 & 15.650 \\
\hline $\begin{array}{l}\text { Number of Jobs in Manufacturing per 1,000 } \\
\text { Residents }^{\mathrm{a}}\end{array}$ & 101.086 & 97 & 9.462 & 196.835 \\
\hline $\begin{array}{l}\text { Number of Government Jobs per } 1000 \\
\text { Residents }\end{array}$ & 68.062 & 37.082 & 33.502 & 230.062 \\
\hline Number of Jobs in Farming per 1000 Resi & 5.607 & 7.351 & 0.000 & 43.976 \\
\hline Business Establishment Density ${ }^{\mathrm{c}}$ & 25.107 & 22.710 & 0.091 & 58.876 \\
\hline \multicolumn{5}{|c|}{$\begin{array}{l}\text { Data: a) Based on Local Area Annual Estimates (BEA 2005) } \\
\text { b) Based on Census of population 1990, 2000. Data for 1993-99 is imputed by linear } \\
\text { extrapolation } \\
\text { c) County Business Patterns (Census Bureau 2005) } \\
\text { Note: Statistics for } 664 \text { population weighted county-level observations. }\end{array}$} \\
\hline
\end{tabular}

jobs. However this correlation is not perfect, which provides an opportunity to use those characteristics as potentially different dimensions of policy effects.

\section{RESULTS}

The estimation results are presented in Tables 3 and 4. Each table contains fixed effect FGLS estimates of policy treatments and control variables on one- and three-year average growth rates. ${ }^{12}$ The selected estimation procedure was compared with random effect and first-difference estimation procedures and was more efficient. ${ }^{13}$ The results of the first-difference and fixed effect estimations are similar, implying that our model provides sufficient control for endogeneity (Wooldridge 2002).

We tested whether the inclusion of the control variables is helpful by regressing the treatment by each policy on the controls and on other policies. The results indicate that the controls are statistically significant in explaining the variations in policy treatment. We found a systematic cross-policy relationship. (See Appendix 1 for details.) For that reason, the policy variables are interacted with each other and de-meaned. ${ }^{14}$ Thus, the estimates represent marginal policy effects on growth in a county with average treatment by other policies.

\footnotetext{
${ }^{12} \operatorname{Stata}^{\mathrm{tm}} 9.0$ was used for estimation.

${ }_{13}^{13}$ As expected when the standard assumptions hold.

${ }^{14}$ Without de-meaning, the estimates would represent the marginal policy effect in a county with no treatment by other policies (interaction term equal to zero in this case).
} 
Nizalov/Loveridge: Regional Policies and Economic Growth

\subsection{Base Model}

The estimates of the policy effects for all Michigan counties (the base model) are presented in Table 3. The results for income growth are in Columns 1 and 2 and for job growth in Columns 3 and 4 . Very few individual policy coefficients are statistically significant. The directions of policy effects on income and job growth are somewhat similar.

The effect of highway improvements is positive but decreasing (the quadratic term is negative) and has a relatively large t-statistic. The results on three-year average job growth (Column 4) imply that one additional mile of highway per 1,000 residents increases the average growth rate by 1.2 percent (for a county with average values of other policy treatments). The effect of every additional mile is decreasing by 0.1 percent. The turning point of 12.6 miles per 1,000 residents is within the range of values in the sample. However, it is far above the state average of 3.8 miles. It implies that highway improvements have the potential to facilitate job growth in most Michigan counties. The effect of highways is higher in counties with larger areas in Renaissance Zones. (The interaction term between the highway's and RZ's treatments is positive and significant.)

Other estimates of the policy effects (which are occasionally significant) do not provide a strong basis for judgment. Policy variables are jointly significant in explaining variations in county growth rate (with exception for one-year income growth - Column 1 - see $\chi^{2}$ statistics for all policy variables at the bottom of the Table 3). The joint policy effect comes primarily through a direct policy impact (as opposed to the interactions with other policies). Interaction terms are jointly significant in affecting the three-year average growth (Columns 2 and $4-\operatorname{see} \chi^{2}$ statistics for policy interactions).

Most of the estimates for the control variables are statistically significant. Since these variables have significant correlation with policy treatments (Appendix 1), they provide a strong control for unobservable policy targeting. The model has sufficient power in explaining variation in growth rates. Both log-likelihood and Wald statistics are high. (See the bottom of the Table 3.)

Even though we found that the policies are jointly significant in explaining income and job growth and that the interactions of their effects are significant, there is not much to say about the effects of individual policies. This is the point where many researchers would stop further investigation of the issue, blaming downward selection bias, lack of reliable instrumental variables, and multicollinearity. However, we hypothesize that policy effects are heterogeneous and change with the type of local economy. This unaccounted heterogeneity hides statistical and practical significance of the policy effects. 
TABLE 3

Base Model

\begin{tabular}{|c|c|c|c|c|}
\hline & \multicolumn{2}{|c|}{ Income Growth } & \multicolumn{2}{|c|}{ Job Growth } \\
\hline & Annual & 3-Year Average & Annual & 3-Year Average \\
\hline & (1) & (2) & (3) & (4) \\
\hline \multirow[t]{2}{*}{ Highway } & 0.003 & -0.053 & 0.443 & 1.220 \\
\hline & $(0.795)$ & $(0.376)$ & $(1.190)$ & $(0.560)^{* *}$ \\
\hline \multirow[t]{2}{*}{ Highway Squared } & -0.055 & -0.031 & -0.084 & -0.097 \\
\hline & $(0.031)^{*}$ & $(0.015)^{* *}$ & $(0.047)^{*}$ & $(0.022)^{* * *}$ \\
\hline \multirow[t]{2}{*}{$\mathrm{RZ}$} & 0.056 & 0.018 & 0.030 & -0.022 \\
\hline & $(0.036)$ & $(0.017)$ & $(0.054)$ & $(0.026)$ \\
\hline \multirow[t]{2}{*}{ RZ Squared } & -0.001 & -0.000 & -0.001 & 0.000 \\
\hline & $(0.000)$ & $(0.000)$ & $(0.001)$ & $(0.000)$ \\
\hline \multirow[t]{2}{*}{ BDA } & 0.034 & -0.046 & -0.106 & -0.035 \\
\hline & $(0.092)$ & $(0.043)$ & $(0.137)$ & $(0.065)$ \\
\hline \multirow[t]{2}{*}{ BDA Squared } & 0.003 & 0.005 & 0.000 & 0.003 \\
\hline & $(0.006)$ & $(0.003)$ & $(0.009)$ & $(0.004)$ \\
\hline \multirow{2}{*}{ MEGA } & 0.006 & -0.263 & 0.497 & 0.096 \\
\hline & $(0.324)$ & $(0.153)^{*}$ & $(0.485)$ & $(0.228)$ \\
\hline \multirow[t]{2}{*}{ MEGA Squared } & 0.016 & 0.058 & -0.042 & 0.006 \\
\hline & $(0.067)$ & $(0.032)^{*}$ & $(0.100)$ & $(0.047)$ \\
\hline \multirow[t]{2}{*}{ Highway *RZ } & 0.002 & 0.001 & 0.003 & 0.002 \\
\hline & $(0.001)^{* *}$ & $(0.000)^{* *}$ & $(0.001)^{* * *}$ & $(0.001)^{* * *}$ \\
\hline \multirow[t]{2}{*}{ Highway *BDA } & 0.002 & 0.003 & 0.009 & 0.007 \\
\hline & $(0.005)$ & $(0.002)$ & $(0.008)$ & $(0.004)^{*}$ \\
\hline \multirow{2}{*}{ Highway *MEGA } & 0.010 & -0.008 & 0.017 & 0.004 \\
\hline & $(0.027)$ & $(0.013)$ & $(0.040)$ & $(0.019)$ \\
\hline \multirow{2}{*}{$\mathrm{RZ} * \mathrm{BDA}$} & -0.001 & -0.001 & -0.000 & -0.001 \\
\hline & $(0.001)$ & $(0.001)$ & $(0.002)$ & $(0.001)$ \\
\hline \multirow[t]{2}{*}{ RZ*MEGA } & 0.045 & 0.020 & -0.044 & -0.010 \\
\hline & $(0.049)$ & $(0.023)$ & $(0.073)$ & $(0.034)$ \\
\hline \multirow[t]{2}{*}{ BDA*MEGA } & 0.002 & 0.042 & 0.038 & 0.006 \\
\hline & $(0.051)$ & $(0.024)^{*}$ & $(0.077)$ & $(0.036)$ \\
\hline \multirow[t]{2}{*}{ Education $_{(t-1)}$} & -0.662 & -0.704 & -0.092 & -0.080 \\
\hline & $(0.527)$ & $(0.249)^{* * * *}$ & $(0.788)$ & $(0.371)$ \\
\hline \multirow[t]{2}{*}{ Manufacturing $_{(t-1)}$} & -0.034 & -0.036 & -0.040 & -0.045 \\
\hline & $(0.017)^{* * 4}$ & $(0.008)^{* * * x}$ & $(0.026)$ & $(0.012)^{* * * *}$ \\
\hline \multirow[t]{2}{*}{ Government $_{(t-1)}$} & -0.023 & -0.027 & -0.042 & -0.057 \\
\hline & $(0.015)$ & $(0.007)^{* * *}$ & $(0.023)^{*}$ & $(0.011)^{* * *}$ \\
\hline \multirow[t]{2}{*}{ Farming $_{(t-1)}$} & 0.040 & 0.020 & -0.151 & -0.087 \\
\hline & $(0.137)$ & $(0.065)$ & $(0.204)$ & $(0.096)$ \\
\hline \multirow[t]{2}{*}{ Business Concentration $_{(t-1)}$} & 0.316 & -0.178 & 0.259 & -0.413 \\
\hline & $(0.364)$ & $(0.172)$ & $(0.544)$ & $(0.256)$ \\
\hline \multirow[t]{2}{*}{ Constant } & -0.970 & -0.249 & 1.326 & 0.741 \\
\hline & $(0.310)^{* * *}$ & $(0.146)^{*}$ & $(0.463)^{* * *}$ & $(0.218)^{* * *}$ \\
\hline
\end{tabular}




\begin{tabular}{|c|c|c|c|c|}
\hline & \multicolumn{2}{|c|}{ Income Growth } & \multicolumn{2}{|c|}{ Job Growth } \\
\hline & Annual & 3-Year Average & Annual & 3-Year Average \\
\hline & (1) & (2) & (3) & (4) \\
\hline Direct Policy: $\chi^{2}$ & 8.44 & $12.23^{*}$ & $12.28^{*}$ & $21.87^{* *}$ \\
\hline Policy int: $\chi^{2}$ & 9.81 & $17.84^{* *}$ & 10.09 & $23.44^{* * *}$ \\
\hline All Policy: $\chi^{2}$ & 19.46 & $40.63^{* * *}$ & $29.14^{* * *}$ & $69.11^{* * *}$ \\
\hline Log likelihood & -1185.34 & -750.11 & -1419.16 & -981.62 \\
\hline Wald $\chi^{2}$ & $232.45^{* * *}$ & $928.67^{* * *}$ & $188.17^{* * *}$ & $419.27^{* * *}$ \\
\hline
\end{tabular}

Standard errors in parentheses. *, ${ }^{* *}$, and $* * *$ significant at $10 \%, 5 \%$, and $1 \%$, respectively. Fixed Effect FGLS estimates presented. Year dummies are suppressed for display purposes. Observations: 581. Number of counties: 83

\subsection{Policy Effect Heterogeneity}

What are the implications of the heterogeneity problem? If this heterogeneity exists but is ignored, the estimation results would present a weighted average of the effects in the separate (relatively homogeneous) sub-regions. The standard error would also be inflated. Moreover, the results will be inconsistent when a larger population is considered and the proportion of the sub-regions changes. To show whether heterogeneity is present, we estimate the model separately for counties with high and low income. A summary of the results is presented in Table 4. Columns 1-4 contain the estimates of the income growth. The estimates of the job growth equation are presented in columns 5-8. Similar separate equations are estimated for metropolitan/non-metropolitan counties and for counties with above and below the median number of jobs in manufacturing. (Results are summarized below.)

Testing the significance of the difference in the estimation results between the subregions involves the following steps. First, we interact the explanatory variables with binary variables for the sub-regions. Second, we insert these new interactions into the model and estimate this augmented model on the full set of observations. Statistical significance of the interactions of the policy variables with the sub-region dummy indicates the significance of the difference in policy effect between the parts of the state under consideration. In the results tables, we have denoted with boldface font the estimates that are individually different at 10 percent significance level between the sub-regions. (Estimates of the difference are not presented in the paper. ${ }^{15}$ ) The joint significance of the differences is assessed with $\chi^{2}$ statistics presented at the bottom of each panel.

\subsubsection{Heterogeneity with Respect to the Income Level}

Our exploration of heterogeneity in policy effects focuses on the differences with respect to income level. The estimation results in Table 4 indicate that the difference in policy effects is statistically significant jointly for the three-year average growth for both income and job growth outcomes. (See $\chi^{2}$ statistics for the difference.) The joint

${ }^{15}$ This and other results not reported in the paper are available from the authors upon request. 
significance of the policy effects on job growth is higher in lower income counties. (See $\chi^{2}$ statistics for all policy variables - Columns 7 and 8.) This implies that difference in income levels is an important source of heterogeneity.

The individual differences in policy effects can be easily seen when the model is estimated separately for high- and low-income counties. The individual difference is observed for most of the variables. Some of these differences are statistically significant. In particular, the BDA effect on the annual growth becomes statistically different between the sub-regions of the state. The effect on annual income growth (Column 1) becomes individually significant in counties with high income. The difference implies that the linear effect is more negative in these areas. The effect becomes positive more quickly than in the low-income counterparts. (The quadratic term is positive and larger.) The effect on the annual income growth becomes positive in the high-income counties after the point of about nine BDA per 100,000 residents. The effect of this policy on the three-year average job growth (Column 8) is positive and significant in low-income counties. Comparing the results for BDAs with the previous table (where no effect was detected), we conclude that uncontrolled heterogeneity of a county economy with respect to the income level hides the significance of this policy effect.

The effect of highways is also found to be different with a larger effect in the highincome counties. Another confirmation to the heterogeneity hypothesis is the fact that the linear effect of the highways on the three-year average income growth differs in sign and magnitude (Columns 2 and 4), while the results from the previous table are insignificant.

Some significant differences in the effects between the high- and low-income counties are found for MEGA and some of the policy interactions. However, none of the $\mathrm{RZ}$ effects becomes statistically significant. The direction of policy effects on income and job growth are consistent with the previous table.

The gain from estimation of individual policy effects by separate sub-regions is not always large. The weakness of heterogeneity evidence (for RZ in particular) is due to several possible reasons. First, the primary source of heterogeneity in the policy effects may be different than the income level. Second, the definition of the sub-regions may be imperfect. Alternatively, there may be no heterogeneity or no significant policy effect. We explore some of these issues in turn.

\subsubsection{Metro/Non-Metro Difference}

We continue the discussion of heterogeneity by considering the difference in the policy effects between metropolitan and non-metropolitan areas. The difference in the joint effect on income growth is significant (results are not presented). This implies that joint policy impact is different in metropolitan and non-metropolitan counties. It serves as additional evidence in favor of the heterogeneity hypothesis. The job growth model is not different statistically. 
TABLE 4

Michigan Development Policy Effects by Income Level

\begin{tabular}{|c|c|c|c|c|c|c|c|c|}
\hline & \multicolumn{4}{|c|}{ Income Growth } & \multicolumn{4}{|c|}{ Job Growth } \\
\hline & \multicolumn{2}{|c|}{ High Income } & \multicolumn{2}{|c|}{ Low Income } & \multicolumn{2}{|c|}{ High Income } & \multicolumn{2}{|c|}{ Low Income } \\
\hline & & 3-Year & & 3-Year & & 3-Year & & 3-Year \\
\hline & Annual & Average & Annual & Average & Annual & Average & Annual & Average \\
\hline & (1) & (2) & (3) & (4) & (5) & (6) & (7) & $(8)$ \\
\hline Highway & $\begin{array}{l}-0.779 \\
(2.012)\end{array}$ & $\begin{array}{l}l^{2.752} \\
(1.046)^{* * *}\end{array}$ & $\begin{array}{c}0.369 \\
(1.081)\end{array}$ & $\begin{array}{l}-0.822 \\
(0.461)^{*}\end{array}$ & $\begin{array}{l}-3.219 \\
(2.794)\end{array}$ & $\begin{array}{c}1.994 \\
(1.346)\end{array}$ & $\begin{array}{c}1.056 \\
(1.776)\end{array}$ & $\begin{array}{c}2.048 \\
(0.816)^{* *}\end{array}$ \\
\hline Highway $^{2}$ & $\begin{array}{l}-0.100 \\
(0.114)\end{array}$ & $\begin{array}{l}-0.023 \\
(0.059)\end{array}$ & $\begin{array}{l}-0.057 \\
(0.042)\end{array}$ & $\begin{array}{l}-0.007 \\
(0.018)\end{array}$ & $\begin{array}{l}-0.093 \\
(0.158)\end{array}$ & $\begin{array}{c}0.075 \\
(0.076)\end{array}$ & $\begin{array}{l}-0.111 \\
(0.069)\end{array}$ & $\begin{array}{c}-0.137 \\
(0.032)^{* * *}\end{array}$ \\
\hline $\mathrm{RZ}$ & $\begin{array}{c}1.112 \\
(0.943)\end{array}$ & $\begin{array}{c}0.293 \\
(0.491)\end{array}$ & $\begin{array}{c}0.037 \\
(0.041)\end{array}$ & $\begin{array}{l}-0.002 \\
(0.018)\end{array}$ & $\begin{array}{c}0.627 \\
(1.310)\end{array}$ & $\begin{array}{c}0.515 \\
(0.631)\end{array}$ & $\begin{array}{c}0.047 \\
(0.068)\end{array}$ & $\begin{array}{l}-0.038 \\
(0.031)\end{array}$ \\
\hline $\mathrm{RZ}^{2}$ & $\begin{array}{c}0.053 \\
(0.049)\end{array}$ & $\begin{array}{c}0.025 \\
(0.026)\end{array}$ & $\begin{array}{l}-0.000 \\
(0.001)\end{array}$ & $\begin{array}{c}0.000 \\
(0.000)\end{array}$ & $\begin{array}{c}0.024 \\
(0.069)\end{array}$ & $\begin{array}{c}0.016 \\
(0.033)\end{array}$ & $\begin{array}{l}-0.001 \\
(0.001)\end{array}$ & $\begin{array}{c}0.000 \\
(0.000)\end{array}$ \\
\hline BDA & $\begin{array}{l}-1.074 \\
(0.603)^{*}\end{array}$ & $\begin{array}{l}-0.352 \\
(0.313)\end{array}$ & $\begin{array}{c}0.160 \\
(0.137)\end{array}$ & $\begin{array}{c}0.011 \\
(0.059)\end{array}$ & $\begin{array}{l}-0.655 \\
(0.837)\end{array}$ & $\begin{array}{l}-0.446 \\
(0.403)\end{array}$ & $\begin{array}{c}0.062 \\
(0.226)\end{array}$ & $\begin{array}{c}0.178 \\
(0.104)^{*}\end{array}$ \\
\hline $\mathrm{BDA}^{2}$ & $\begin{array}{c}0.120 \\
(0.043)^{* * *}\end{array}$ & $\begin{array}{c}0.011 \\
(0.022)\end{array}$ & $\begin{array}{c}-0.005 \\
(0.007)\end{array}$ & $\begin{array}{c}0.002 \\
(0.003)\end{array}$ & $\begin{array}{c}0.078 \\
(0.060)\end{array}$ & $\begin{array}{c}0.029 \\
(0.029)\end{array}$ & $\begin{array}{l}-0.006 \\
(0.012)\end{array}$ & $\begin{array}{l}-0.005 \\
(0.005)\end{array}$ \\
\hline MEGA & $\begin{array}{c}4.605 \\
(3.082)\end{array}$ & $\begin{array}{c}1.799 \\
(1.603)\end{array}$ & $\begin{array}{l}-0.271 \\
(0.364)\end{array}$ & $\begin{array}{l}-0.348 \\
(0.155)^{* *}\end{array}$ & $\begin{array}{c}0.429 \\
(4.279)\end{array}$ & $\begin{array}{c}1.168 \\
(2.062)\end{array}$ & $\begin{array}{c}0.556 \\
(0.599)\end{array}$ & $\begin{array}{c}0.036 \\
(0.275)\end{array}$ \\
\hline MEGA $^{2}$ & $\begin{array}{l}-0.415 \\
(0.217)^{*}\end{array}$ & $\begin{array}{l}-0.206 \\
(0.113)^{*}\end{array}$ & $\begin{array}{c}0.054 \\
(0.081)\end{array}$ & $\begin{array}{c}0.079 \\
(0.034)^{* *}\end{array}$ & $\begin{array}{c}0.076 \\
(0.301)\end{array}$ & $\begin{array}{l}-0.063 \\
(0.145)\end{array}$ & $\begin{array}{l}-0.072 \\
(0.133)\end{array}$ & $\begin{array}{c}0.001 \\
(0.061)\end{array}$ \\
\hline Highway *RZ & $\begin{array}{c}0.072 \\
(0.070)\end{array}$ & $\begin{array}{c}0.008 \\
(0.036)\end{array}$ & $\begin{array}{c}0.002 \\
(0.001)^{* *}\end{array}$ & $\begin{array}{c}0.001 \\
(0.000)^{*}\end{array}$ & $\begin{array}{c}0.094 \\
(0.097)\end{array}$ & $\begin{array}{c}0.051 \\
(0.047)\end{array}$ & $\begin{array}{c}0.004 \\
(0.002)^{* *}\end{array}$ & $\begin{array}{c}0.003 \\
(0.001)^{* * *}\end{array}$ \\
\hline Highway *BDA & $\begin{array}{l}-0.030 \\
(0.020)\end{array}$ & $\begin{array}{c}0.007 \\
(0.011)\end{array}$ & $\begin{array}{l}-0.000 \\
(0.006)\end{array}$ & $\begin{array}{c}0.001 \\
(0.003)\end{array}$ & $\begin{array}{l}-0.007 \\
(0.028)\end{array}$ & $\begin{array}{c}0.001 \\
(0.014)\end{array}$ & $\begin{array}{c}0.007 \\
(0.010)\end{array}$ & $\begin{array}{c}0.003 \\
(0.004)\end{array}$ \\
\hline Highway *MEGA & $\begin{array}{c}0.095 \\
(0.054)^{*}\end{array}$ & $\begin{array}{c}0.014 \\
(0.028)\end{array}$ & $\begin{array}{l}-0.008 \\
(0.035)\end{array}$ & $\begin{array}{l}-0.021 \\
(0.015)\end{array}$ & $\begin{array}{l}-0.015 \\
(0.075)\end{array}$ & $\begin{array}{c}0.002 \\
(0.036)\end{array}$ & $\begin{array}{c}0.037 \\
(0.057)\end{array}$ & $\begin{array}{c}0.007 \\
(0.026)\end{array}$ \\
\hline $\mathrm{RZ} * \mathrm{BDA}$ & $\begin{array}{l}-0.261 \\
(0.232)\end{array}$ & $\begin{array}{l}-0.108 \\
(0.120)\end{array}$ & $\begin{array}{l}-0.002 \\
(0.001)\end{array}$ & $\begin{array}{l}-0.001 \\
(0.001)\end{array}$ & $\begin{array}{l}-0.024 \\
(0.322)\end{array}$ & $\begin{array}{l}-0.055 \\
(0.155)\end{array}$ & $\begin{array}{l}-0.001 \\
(0.002)\end{array}$ & $\begin{array}{l}-0.001 \\
(0.001)\end{array}$ \\
\hline RZ*MEGA & $\begin{array}{c}1.157 \\
(1.211)\end{array}$ & $\begin{array}{c}0.515 \\
(0.630)\end{array}$ & $\begin{array}{c}0.023 \\
(0.051)\end{array}$ & $\begin{array}{c}0.018 \\
(0.022)\end{array}$ & $\begin{array}{c}0.328 \\
(1.681)\end{array}$ & $\begin{array}{c}0.368 \\
(0.810)\end{array}$ & $\begin{array}{l}-0.040 \\
(0.084)\end{array}$ & $\begin{array}{l}-0.004 \\
(0.039)\end{array}$ \\
\hline
\end{tabular}




\begin{tabular}{|c|c|c|c|c|c|c|c|c|}
\hline & \multicolumn{4}{|c|}{ Income Growth } & \multicolumn{4}{|c|}{ Job Growth } \\
\hline & \multicolumn{2}{|c|}{ High Income } & \multicolumn{2}{|c|}{ Low Income } & \multicolumn{2}{|c|}{ High Income } & \multicolumn{2}{|c|}{ Low Income } \\
\hline & & 3-Year & & 3-Year & & 3-Year & & 3-Year \\
\hline & Annual & Average & Annual & Average & Annual & Average & Annual & Average \\
\hline & (1) & (2) & (3) & (4) & (5) & (6) & (7) & $(8)$ \\
\hline \multirow[t]{2}{*}{ BDA*MEGA } & -0.036 & 0.089 & -0.062 & -0.004 & 0.224 & 0.109 & -0.040 & -0.067 \\
\hline & $(0.090)$ & $(0.047)^{*}$ & $(0.065)$ & $(0.028)$ & $(0.124)^{*}$ & $(0.060)^{*}$ & $(0.107)$ & $(0.049)$ \\
\hline All Policy: $\chi^{2}$ & 19.31 & $25.86^{* *}$ & 13.98 & $34.42^{* * *}$ & 9.94 & 17.62 & $25.30^{* *}$ & $62.99^{* * * *}$ \\
\hline Difference: $\chi^{2}$ & 19.33 & $29.66^{* * *}$ & & & 10.58 & $25.34^{* *}$ & & \\
\hline Log likelihood & -554.08 & -361.81 & -594.35 & -349.96 & -650.54 & -435.85 & -736.99 & -513.79 \\
\hline Wald $\chi^{2}$ & $239.30^{* * *}$ & $704.74^{* * *}$ & $109.36^{* * *}$ & $433.34^{* * *}$ & $112.18^{* * *}$ & $297.68^{* * *}$ & $111.71^{* * *}$ & $211.09^{* * *}$ \\
\hline Observations & 294 & 294 & 287 & 287 & 294 & 294 & 287 & 287 \\
\hline Number of & 42 & 42 & 41 & 41 & 42 & 42 & 41 & 41 \\
\hline $\begin{array}{l}\text { Standard errors } \\
\text { variables are su } \\
\text { individually sig }\end{array}$ & $\begin{array}{l}\text { heses. *, * } \\
\text { for display } \\
\text { it } 10 \% \text { lev }\end{array}$ & $\begin{array}{l}* * * \text { sign } \\
\text { oses. Est }\end{array}$ & $10 \%, 5 \%$ & $0, r$ & Fixed Eff & S estima & cedure is & $\begin{array}{l}\text { ontrol } \\
\text { income is }\end{array}$ \\
\hline
\end{tabular}


The individual difference is most obvious (and significant) for the effect of RZ on income growth and highways on job growth. The effect of RZ on three-year average income growth in metropolitan counties becomes positive and significant, but at a decreasing rate. The turning point is around 26 acres of zone per 1,000 metropolitan residents. This point is within the range of the treatment values but is far above the average of 0.7 acres. This implies that metropolitan counties can benefit more from application of this policy. Also, an increase in application of this policy in counties with more than 26 acres per 1,000 residents is counterproductive.

The effect of the highways on job growth is higher in non-metropolitan counties. It is positive but at a decreasing rate. The turning point is around 13-16 miles per 1,000 non-metropolitan residents for both the annual and three-year average growth. This point stays within the range of the policy treatment values in the sample but is above the average. This result implies that highway improvements are an effective tool in stimulating job growth in non-metropolitan areas. Considering this along with the RZ results, we can also conclude that the source of heterogeneity is different for different policies, but heterogeneity stays as a significant source of error in estimation results that hides the true policy effect.

\subsubsection{Heterogeneity with Respect to Industry Structure}

Heterogeneity of policy effects with respect to industrial structure of the local economy adds one more dimension to the analysis. The results are similar to the case of metropolitan/non-metropolitan heterogeneity. However, the policy effects are not significantly different among the sub-regions (with few exceptions).

Even though statistical and practical significance is observed, results should be interpreted with caution. The measures of heterogeneity are far from perfect. For example, Papke (1991) shows that the effect of infrastructure varies significantly across industries within the manufacturing sector. The measure of urbanization used in this study might not capture all the differences between urban, fringe, and rural areas. Also, other sources of heterogeneity, such as unemployment rate, are possible. For example, while Bartik (1991) and other authors (e.g., Goss and Phillips 1999) argue that the policy effect should be higher in regions with higher unemployment rates due to higher social benefits, others argue that when policies stimulate labor demand under low unemployment, more people would be attracted to the labor force and thus the effect should be higher under low unemployment.

Measures of the policy treatment could also be better. Highway miles do not measure all of the changes in quality of the infrastructure. Moreover, selection bias might not be completely excluded. In addition, there are costs associated with the use of the policy tools, which may offset the benefits. Those costs are not controlled for in our model. 
The measures of growth also have weaknesses. Averaging reduces all of the shortterm effects. If a policy has an effect on, for example, one-year growth but with some time lead, this effect would be underestimated. On the other hand, averaging reveals longer-term effects even if they are relatively small comparative to the short-run noise. Nevertheless, the results provide some insight on how the policy effects change over time and space.

\section{CONCLUSIONS}

In this paper, we implemented a quantitative assessment of the impact of Michigan economic development policies and highway infrastructure improvements on personal income and job growth. We find that the policies have significant impact on the growth outcomes. However, the effects vary across different types of local economies. Ignoring this heterogeneity leads to underestimation of the policy effects. Significantly different policy effects are detected between areas with high and low levels of income and different urban structure. The lines along which the individual policy effect may change are different for different policies. For example, Brownfield Development Authority treatment is more beneficial for low-income communities, which may lack sufficient market pressure for redevelopment of underutilized land resources. The highways benefit more non-metropolitan counties where the reduction of transportation cost may be more significant. Renaissance Zones benefit more metropolitan counties. The difference in the Renaissance Zone's effect may be due to the relatively higher benefits provided by the policy in metropolitan areas where businesses and residents may experience higher tax loads and where agglomeration effects may be higher. While determining the precise sources of heterogeneity requires additional study, it is clear from our results that economic development resources can be used more efficiently if policies target the areas most likely to produce higher returns.

The marginal effects of policies change with the scale of policy treatment, implying that there is a minimum threshold necessary for a positive impact. Also, there is a point after which policies become counterproductive. Significant interactions between the policy effects are detected. The results imply that the policies have mutually reinforcing effects in most of the cases.

The policies have little correlation with fluctuations in annual growth. However, they change more persistent growth patterns as measured by the three-year average growth rate.

Some of the results have broader implications. A policy treatment such as a Renaissance Zone can be considered as a change in tax regime external to local residents and businesses. Thus, implementation of the policy can be treated as a "natural experi- 
ment."16 The results imply that lower taxes stimulate local growth holding fixed other factors (such as quality of infrastructure and public services).

Comparison of policy effects on alternative growth outcomes opens a wide range of opportunities for analysis. Job growth should correspond to income growth trends since wage is a part of personal income. Keeping this in mind, we can look at the difference in policy effects between income and job growth as changes in income distribution patterns. For example, if we observe a positive effect on job growth but not on income growth, we can suspect that either some of the jobs go to commuters or that a substitution effect in the sources of income takes place (e.g., unemployment subsidies are substituted with some wage income without raising well-being). The other extreme point would be when we observe a positive effect on income growth without growth or even with decline in the number of jobs. This situation implies that the source of income growth is either an increase in property value, or increase in proprietary income, or substitution of labor for other factors. The ideal policy would have a positive impact on both growth outcomes. Our results show that, in general, Michigan policies have similar impact on both income and job growth. It implies that Michigan economic development efforts are beneficial to the well being of state residents. However, more rigorous analysis of this issue is required.

In the light of the current trends in economic development when communities, especially in rural areas, are increasingly vulnerable to globalization processes, it is extremely important to tailor development policies to the specifics of the targeted areas. Our results show that a one-size-fits-all approach is not appropriate for regional economic development. The results can be used to set priorities among different policy tools and contribute to better understanding of the development policy effects. They also allow a more accurate expectation of the policy impact.

\section{REFERENCES}

Bartik, T.J., 1991. Who Benefits from State and Local Economic Development Policies? Upjohn Institute for Employment Research: Kalamazoo, MI. , 1997. "Discussion," New England Economic Review March/April, 67-71.

Bartik, T.J., P. Eisinger, and G. Erickcek, 2003. "Economic Development Policy in Michigan," in C. Ballard, P. Courant, D. Drake, R. Fisher, and E. Gerber (eds.), Michigan at the Millennium (pp. 279-297). Michigan State University Press: East Lansing, MI.

Besley, T. and A. Case, 2000. "Unnatural Experiments? Estimating the Incidence of Endogenous Policies," Economic Journal 110(November), F672-94.

Bradshaw, T., 2002. "The Contribution of Small Business Loan Guarantees to Economic Development," Economic Development Quarterly 16(4), 360-369.

\footnotetext{
${ }^{16}$ Bartik $(1991,1997)$ argues that taxes and public spending are highly endogenous to growth, and without an external shock it is impossible to determine their impact with any precision.
} 
Bureau of Economic Analysis, 2005. Local Area Annual Estimates. Available at: www.bea.gov, January.

Buss, T.F., 2001. "The Effect of State Tax Incentives on Economic Growth and Firm Location Decisions: An Overview of the Literature," Economic Development Quarterly 15(1), 90-105.

Citizens Research Council of Michigan, 1998. Michigan Renaissance Zones in the Economic Development Context. Report No. 324, November. 2001. Survey of Economic Development Programs in Michigan. Report No. 334, May.

Census Bureau, 2000. Decennial Census of Population and Housing. U.S. Department of Commerce. Available at: www.census.gov , January. , 2005. County Business Patterns. U.S. Department of Commerce. Available at: www.census.gov, January.

Dalenberg, D.R. and M.D. Partridge, 1995. "The Effect of Taxes, Expenditures, and Public Infrastructure on Metropolitan Employment," Journal of Regional Science 35(4), 617-640.

DeSousa, C., 2000. "Brownfield Redevelopment versus Greenfield Development: A Private Sector Perspective on the Costs and Risks Associated with Brownfield Redevelopment in the Greater Toronto Area," Journal of Environmental Planning and Management 43(6), 831-853.

Dewar, M.E., 1998. "Why State and Local Economic Development Programs Cause So Little Economic Development," Economic Development Quarterly 12(1), 68-87.

Faulk, D., 2002. "Do State Economic Development Incentives Create Jobs? An Analysis of State Employment Tax Credits," National Tax Journal 55, 263-280.

Fisher, R.C., 1997. "The Effect of State and Local Public Services on Economic Development," New England Economic Review March/April, 53-67.

Fisher, P. and A. Peters, 1997. "Tax and Spending Incentives and Enterprise Zones," New England Economic Review March/April, 109-130.

Forni, M. and M. Lippi, 1997. Aggregation and the Microfoundations of Dynamic Macroeconomics. Clarendon Press: Oxford.

Goetz, S., 1999. "Migration and Local Labor Markets," in S. Loveridge (ed.), The Web Book of Regional Science, Regional Research Institute, West Virginia University.

Goss, E. and J. Phillips, 1999. "Do Business Tax Incentives Contribute to a Divergence in Economic Growth?" Economic Development Quarterly 13(3), 217-228.

Loh, E., 1993. "The Effects of Job-Targeted Development Incentive Programs," Growth and Change 24, 365-383.

Luce, T.F., Jr., 1994. "Local Taxes, Public Services and Firm Location," Public Finance Quarterly 22(2), 139-176.

Mayer, P. and T. Lyons, 2000. "Lessons from Private Sector Brownfield Redevelopers: Planning Public Support for Urban Regeneration," Journal of the American Planning Association 66(1), 46-57

Papke, L., 1991. "Interstate Business Tax Differentials and New Firm Location: Evidence from Panel Data," Journal of Public Economics 45, 47-68. , 1993. "What Do We Know about Enterprise Zones?" in J. Poterba (ed.), Tax Policy and the Economy 7, 37-72. 
, 1994. "Tax Policy and Urban Development: Evidence from the Indiana Enterprise Zone Program," Journal of Public Economics 54, 37-49.

Sadoulet, E. and A. de Janvry, 1995. Quantitative Development Policy Analysis. The Johns Hopkins University Press: Baltimore.

Site Selection, various issues. Conway Data Inc.

Thornburgh, D., 1998. "A Path of Smarter Federal Leadership in Economic Development: Learning, Leveraging, and Linking," Economic Development Quarterly 12(4), 291-298.

Tolbert, C.M. and M. Sizer, 1996. "U.S. Commuting Zones and Labor Market Areas: A 1990 Update," Economic Research Service, Staff Paper No. AGES-9614, September, 39.

Wasylenko, M., 1997. "Taxation and Economic Development," New England Economic Review March/April, 37-52.

Wolcoff, M., 1992. “Is Economic Development Decision Making Rational?" Urban Affairs Quarterly 27(3), 340-355.

Wooldridge J.M., 2002. Econometric Analysis of Cross Section and Panel Data, MIT Press: Cambridge, MA.

\section{APPENDIX 1. MODEL SPECIFICATION}

Whether the control variables explain non-random variations in policy treatment caused by targeting can be verified. We estimate the correlation between the policy treatment and the controls. Table A1 presents the results of this estimation. It shows a significant correlation between the treatment and other variables included in the models, which supports a concern about non-random policy placement. It also shows a systematic relationship among the policy treatments. For example, areas with higher per capita highway mileage have more of BDA per capita (coefficient on highways in the BDA equation is positive - Column 3). On the other hand, there are fewer MEGAs in areas with more RZ (coefficient on RZ is negative - Column 4), holding other factors fixed.

Regarding the controls, a higher level of education associates with fewer applications of MEGA but more BDA. Characteristics of county industry structure are also significant in explaining the variations in the amount of policy treatment. A negative coefficient on business concentration indicates that the policies systematically target areas with fewer business establishments, holding other factors fixed. Joint significance of the control variables is also high. (See $\chi^{2}$ statistics at the bottom of the table.) Thus, the use of the above-mentioned controls improves results of the policy analysis. 


\section{TABLE A1}

Intensity of Policy Application

\begin{tabular}{|c|c|c|c|c|}
\hline & $\begin{array}{c}(1) \\
\text { Highway }\end{array}$ & $\begin{array}{l}(2) \\
\text { RZ }\end{array}$ & $\begin{array}{c}(3) \\
\text { BDA }\end{array}$ & $\begin{array}{c}(4) \\
\text { MEGA }\end{array}$ \\
\hline Highway & & $\begin{array}{c}3.856 \\
(2.354)\end{array}$ & $\begin{array}{c}0.748 \\
(0.409)^{*}\end{array}$ & $\begin{array}{l}-0.214 \\
(0.209)\end{array}$ \\
\hline $\mathrm{RZ}$ & $\begin{array}{c}0.001 \\
(0.001)\end{array}$ & & $\begin{array}{l}0.038 \\
(0.007)^{* * *}\end{array}$ & $\begin{array}{l}-0.010 \\
(0.004)^{* * *}\end{array}$ \\
\hline BDA & $\begin{array}{c}0.008 \\
(0.004)^{*}\end{array}$ & $\begin{array}{l}1.240 \\
(0.233)^{* * *}\end{array}$ & & $\begin{array}{l}0.042 \\
(0.021)^{* *}\end{array}$ \\
\hline MEGA & $\begin{array}{l}-0.008 \\
(0.008)\end{array}$ & $\begin{array}{l}-1.252 \\
(0.465)^{* * *}\end{array}$ & $\begin{array}{c}0.162 \\
(0.081)^{* *}\end{array}$ & \\
\hline Education $_{(t-1)}$ & $\begin{array}{c}0.047 \\
(0.041)\end{array}$ & $\begin{array}{l}-1.338 \\
(2.361)\end{array}$ & $\begin{array}{l}1.918 \\
(0.403)^{* * *}\end{array}$ & $\begin{array}{l}-0.458 \\
(0.208)^{* *}\end{array}$ \\
\hline Manufacturing $_{(t-1)}$ & $\begin{array}{l}0.006 \\
(0.001)^{* * *}\end{array}$ & $\begin{array}{l}-0.269 \\
(0.076)^{* * *}\end{array}$ & $\begin{array}{l}0.029 \\
(0.013)^{* *}\end{array}$ & $\begin{array}{c}0.001 \\
(0.007)\end{array}$ \\
\hline Government $_{(\mathrm{t}-1)}$ & $\begin{array}{l}0.005 \\
(0.001)^{* * *}\end{array}$ & $\begin{array}{l}-0.047 \\
(0.065)\end{array}$ & $\begin{array}{l}0.047 \\
(0.011)^{* * *}\end{array}$ & $\begin{array}{l}-0.032 \\
(0.006)^{* * *}\end{array}$ \\
\hline Farming $_{(\mathrm{t}-1)}$ & $\begin{array}{c}0.015 \\
(0.011)\end{array}$ & $\begin{array}{l}1.373 \\
(0.611)^{* *}\end{array}$ & $\begin{array}{c}0.187 \\
(0.106)^{*}\end{array}$ & $\begin{array}{l}0.128 \\
(0.054)^{* *}\end{array}$ \\
\hline Business Concentration $_{(t-1)}$ & $\begin{array}{l}-0.083 \\
(0.029)^{* * *}\end{array}$ & $\begin{array}{l}-3.748 \\
(1.630)^{* *}\end{array}$ & $\begin{array}{l}-0.778 \\
(0.283)^{* * *}\end{array}$ & $\begin{array}{l}-0.076 \\
(0.145)\end{array}$ \\
\hline Constant & $\begin{array}{l}-0.034 \\
(0.024)\end{array}$ & $\begin{array}{l}-4.785 \\
(1.356)^{* * *}\end{array}$ & $\begin{array}{c}0.246 \\
(0.238)\end{array}$ & $\begin{array}{l}-0.629 \\
(0.119)^{* * *}\end{array}$ \\
\hline Controls: $\chi^{2}$ & $50.44^{* * *}$ & $31.85^{* * *}$ & $60.77^{* * *}$ & $50.50^{* * *}$ \\
\hline $\begin{array}{l}\text { Log likelihood } \\
\text { Wald } \chi^{2}\end{array}$ & $\begin{array}{l}279.45 \\
180.19^{* * *}\end{array}$ & $\begin{array}{c}-2068.17 \\
119.53^{* * *}\end{array}$ & $\begin{array}{c}-1052.03 \\
366.70^{* * *} \\
\end{array}$ & $\begin{array}{l}-660.16 \\
165.56^{* * *}\end{array}$ \\
\hline $\begin{array}{l}\text { Standard errors in parenthe } \\
\text { Effect FGLS estimation pro } \\
\text { Observations: } 581 \text {. Number }\end{array}$ & $\begin{array}{l}\text { and *** } \\
\text { used. Ye } \\
\text { ec. } 83\end{array}$ & int at $10 \%$, & d $1 \%$, respe & $\begin{array}{l}\text { y. Fixed } \\
\text { oses. }\end{array}$ \\
\hline
\end{tabular}

